\title{
Role of endonuclease $G$ in senescence-associated cell death of human endothelial cells
}

Running title: EndoG in HUVEC senescence

Thomas Diener ${ }^{1}$, Michael Neuhaus ${ }^{1}$, Rafal Koziel ${ }^{1}$, Lucia Micutkova ${ }^{1}$, Pidder JansenDürr ${ }^{1}$

${ }^{1}$ Institute for Biomedical Aging Research, Austrian Academy of Sciences, Rennweg 10, A-6020 Innsbruck, Austria

*Address correspondence to: Dr. Pidder Jansen-Dürr, Institute for Biomedical Aging Research, Rennweg 10, A-6020 Innsbruck, Austria, Phone: +43-512-583919-44, FAX: +43-512-583919-8, email: p.jansen-duerr@oeaw.ac.at

Keywords: HUVEC;EndoG;Senescence;Apoptosis. 


\section{Abstract}

Mitotic cells in culture show a limited replicative potential and after extended subculturing undergo a terminal growth arrest termed cellular senescence. When cells reach the senescent phenotype, this is accompanied by a significant change in the cellular phenotype and massive changes in gene expression, including the upregulation of secreted factors. In human fibroblasts, senescent cells also acquire resistance to apoptosis. In contrary, in human endothelial cells, both replicative and stress-induced premature senescence is accompanied by increased cell death; however mechanisms of cell death are poorly explored. In this communication, we addressed the role of endonuclease $G$ (EndoG), a mitochondrial mediator of caspase-independent cell death, in senescence-associated cell death of human endothelial cells. Using immunofluorescence microscopy, we found, that EndoG is localized in the mitochondria in young cells, but relocalizes to the nucleus upon senescence. When EndoG gene expression was downregulated by lentiviral shRNA vectors, we found a significant reduction in the replicative life span and a corresponding increase in cell death. We also observed a slight shift in the cell death phenotype from necrosis to apoptosis. Together these observations suggest an important role of EndoG in the senescence program of human endothelial cells. 


\section{Introduction}

Human ageing is accompanied by a degeneration of various tissues, which loose part of their physiological functions. Tissue degeneration is often accompanied by the loss of specialized cell types. In some cases, this is due to an exhaustion of the cell division capacity, as is best documented for ageing of the immune system (for review, see (Effros, 1996)) and for part of the skin ageing program (for review, see (Campisi, 1998)). Programmed cell death (apoptosis) apparently plays an important role during ageing of various tissues in vivo (for review, see (Warner et al., 1997)), and mice with a genetic defect in stress-related apoptosis display a significantly extended lifespan (Migliaccio et al., 1999). Tissue damage caused by age-dependent apoptosis has been documented in experimental animals (Adams et al., 1996; Nicosia et al., 1995; Usami et al., 1997). It is assumed that apoptosis plays an important role in tissue homeostasis, and the failure of cells to exert the apoptotic program can also lead to disorders which accumulate during ageing. For example, it was suggested that decreased efficiency of apoptosis contributes to the alterations characteristic of intrinsic (chronologic ageing) and extrinsic (photoageing) skin ageing (Haake et al., 1998). Together, these results suggest that regulation of programmed cell death plays an important role for the ageing process in vivo; however, the role of apoptosis for ageing may differ between various tissues.

Concerning human ageing, many questions about molecular mechanisms have been addressed using in vitro senescence models derived from normal human cells. The proliferative potential of human primary cells in culture is limited, and extended passaging of such cells leads to a state of terminal growth arrest, referred to as replicative senescence. While the erosion of telomeres, due to insufficient telomerase activity (for review, see (Shawi and Autexier, 2008)), has been recognized as a 
primary cause of replicative cellular senescence, a variety of other events have been identified that trigger premature senescence. Most notably, oxidative stress was found to induce premature senescence in human fibroblasts (Chen and Ames, 1994; von Zglinicki et al., 1995), endothelial cells (Kurz et al., 2004; Unterluggauer et al., 2003), and a variety of other cell types (reviewed in ref. (Colavitti and Finkel, 2005)).

It was shown that senescent fibroblasts are resistant to apoptosis (Wang, 1995), and p53-dependent apoptotic pathways are specifically blocked in senescent fibroblasts. Stabilization of p53 in response to DNA damage is impaired in old fibroblasts, resulting in induction of necrosis (Seluanov et al., 2001). While these results suggest a specific impairment of proapoptotic signalling in senescent fibroblasts, we found that human endothelial cells undergo age-associated cell death during in vitro ageing (Hampel et al., 2004; Wagner et al., 2001) and this was confirmed for bovine endothelial cells in independent experiments (Zhang et al., 2002).

Apoptotic cell death can be triggered by a wide variety of environmental stimuli and the apoptotic response of a given cell is modified by a plethora of cellular gene products. The current knowledge in this field can be briefly summarized as follows: Apoptosis triggered by cell death receptors (e.g. the Fas/Fas ligand system) leads to the activation of a class of proteases, referred to as caspases, in particular caspase 8 and 10, which activate effector caspases (e.g. caspases 3, 6 or 7) (Nicholson, 1999). Effector caspases then cleave key substrates and thereby cause nuclear fragmentation. In an alternative pathway, mitochondrial function is altered through a variety of signals, ultimately leading to the opening of the mitochondrial permeability transition pore (PTP). PTP opening is modulated, among others, by members of the Bcl-2 gene family (for review, see (Bernardi et al., 2001)). Subsequently, soluble factors are released from the mitochondria to trigger an apoptotic response. These 
factors include cytochrome C which, in combination with Apaf-1 (Zou et al., 1997), leads to activation of caspase 9, which then activates effector caspases, such as caspase 3 (Bratton et al., 2001). Simultaneously, other proapoptotic proteins, such as Smac (DIABLO), apoptosis inducing factor (AIF), and endonuclease G, are released from the mitochondria (Li et al., 2001; Parrish et al., 2001).

Endonuclease $G$ is a member of the conserved DNA/RNA non-specific $\beta \beta \alpha-M e$-finger nuclease family which is located exclusively in the mitochondrial intermembrane space (Cote and Ruiz-Carrillo, 1993; Schafer et al., 2004) for recent review, see (Varecha et al., 2007). It is translated as a $~ 33 \mathrm{kDa}$ preprotein and cleaved upon translocation into the mitochondria to a $\sim 28 \mathrm{kDa}$ protein, forming an active homodimer nuclease. EndoG was first isolated from calf thymus and is highly specific for $(d G) n .(d C) n$ tracts in DNA which was first thought to be important in mitochondrial replication (Cote et al., 1989). Homologues have been described in many model organisms such as C. elegans (Parrish et al., 2001), M. musculus (Li et al., 2001), S. cerevisiae (Buttner et al., 2007a). The catalysis of phosphodiesters is dependent on the conserved residues His143, Asn174, and Glu182 which are necessary for metal binding while Arg141 is important for substrate binding (Schafer et al., 2004). In mouse embryonic fibroblasts, EndoG is translocated into the nucleus upon apoptotic stimuli and cleaves DNA chromatin into nucleosomal fragments which is not dependent on caspases ( $\mathrm{Li}$ et al., 2001). Extramitochondrial expression of active EndoG causes cell death in HeLa cells, while expression of EndoG, mutated in the active centre, does not (Schafer et al., 2004). Also in yeast, overexpression of the EndoG homolog (Nuc1p) leads to cell death (Buttner et al., 2007a). 


\section{Materials and methods}

\subsection{Cell culture}

Endothelial cells of two different donors were isolated from human umbilical veins and maintained on gelatine covered plates in Endothelial Cell Medium (Cambrex BioScience) in $5 \% \mathrm{CO}_{2}$ at $37^{\circ} \mathrm{C}$ as described in (Unterluggauer et al., 2003). Cells were passaged when $70-80 \%$ of confluence was reached. Population doublings (PDL) were estimated using the following equation: $n=\left(\log _{10} F-\log _{10} I\right) / 0.301$ (with $n=$ population doublings, $F=$ number of cells at the end of one passage, $l=$ number of cells that were seeded at the beginning of one passage). After roughly 20 population doublings, the cells reached growth arrest. The senescent status was verified by in situ staining for SA- $\beta$-galactosidase as described (Dimri et al., 1995).

For production of lentiviral particles, HEK-293T cells [human embryonic kidney 293 cells expressing the large T-antigen of SV40 (simian virus 40)] were maintained in DMEM (Dulbecco's modified Eagle's medium) containing 2 mM L-glutamine, 100 units $/ \mathrm{ml}$ penicillin, $0.1 \mathrm{mg} / \mathrm{ml}$ streptomycin and $10 \%(\mathrm{w} / \mathrm{v})$ fetal bovine serum (heatinactivated).

The research has been performed in accordance with the Declaration of Helsinki (2000) of the World Medical Association and has been approved by the Ethics Committee of the Innsbruck Medical University. Consent was obtained from each patient after full explanation of the purpose, nature and risk of all procedures.

\subsection{Lentiviral gene knockdown}

Production of lentiviral particles was carried out according to the manufacturer's protocol (Addgene) using the packaging plasmids pMD2.G and psPAX2 (both 
purchased from Addgene) and the lentiviral vector pLKO.1, containing EndoGspecific shRNA (small-hairpin RNA) and control (scrambled) shRNA, respectively (Open Biosystems). For lentiviral infection, early passage HUVEC were cultivated in six-well plates. Upon reaching $~ 70 \%$ confluence, culture medium, containing lentiviral particles to the amount of $2 \mathrm{MOI}$ (multiplicity of infection), was added to the cells in presence of $8 \mu \mathrm{g} / \mathrm{ml}$ hexadimethrine bromide (Sigma-Aldrich), which increases the efficiency of viral infection. At $24 \mathrm{~h}$ after infection, medium was changed. Puromycin selection was initiated $(500 \mathrm{ng} / \mathrm{ml}) 72 \mathrm{~h}$ post infection.

\subsection{Measurement of mitochondrial membrane potential}

The electric potential of the inner mitochondrial membrane was measured in situ using flow cytometry in intact cells stained with $\mathrm{JC}-1$ fluorescent probe (Cossarizza, 1993).

HUVECs were detached, cell number counted and 100000 cells used for analysis. Cells were resuspended in EGM containing $0.5 \mu \mathrm{g} / \mathrm{ml} \mathrm{JC}-1$. Positive control was treated additionally with $5 \mu \mathrm{M}$ FCCP. Cells were incubated for 30 min at $37^{\circ} \mathrm{C}$, washed once with PBS containing $1 \mathrm{mM}$ pyruvate and $5 \mathrm{mM}$ glucose and resuspended in $300 \mu \mathrm{l}$ PBS. JC-1 fluorescence was measured using a flow cytometer (BD FACSCanto ${ }^{\mathrm{TM}}$ II) (excitation with an argon laser at $488 \mathrm{~nm}$ and emission wavelength of $530 / 590 \mathrm{~nm})$.

\subsection{FACS analysis of cell death}

For detection of apoptosis, HUVECs were detached and incubated in a fluorochrome buffer containing $0.1 \%(\mathrm{v} / \mathrm{v})$ Triton-X-100, $50 \mu \mathrm{g} / \mathrm{ml}$ propidium iodide, dissolved in $\mathrm{ddH}_{2} \mathrm{O}$. Cells were incubated for $30 \mathrm{~min}$ at $4^{\circ} \mathrm{C}$, then analysed in FACS (BD FACSCanto $^{\mathrm{TM}}$ II)(Nicoletti et al., 1991). For necrosis quantification, HUVECs were 
detached and resuspended in $300 \mu \mathrm{l}$ buffer containing $10 \mathrm{mM}$ Hepes, $140 \mathrm{mM}$ sodium chloride, $2.5 \mathrm{mM} \mathrm{CaCl}_{2}, \mathrm{pH}$ 7.4. Shortly before FACS measurement $1 \mu \mathrm{l}$ propidium iodide $(1 \mu \mathrm{g} / \mu \mathrm{l})$ was added. Measurement was done with and without addition of PI.

\subsection{Immunofluorescence}

HUVEC were seeded on glass slides (diameter 13mm) in six-well-plates using 100 000 early passage cells or 50000 late passage cells. On the following day cells were washed and fixed in 4\% paraformaldehyde in PBS for 20 min at RT. Glass slides were transferred into 24 -wells and cells were permeabilized with $0.1 \%$ Triton-X-100 and $0.1 \%$ sodium citrate diluted in PBS for 2 min on ice. Cells were washed with PBS and incubated in blocking buffer (1\% BSA in PBS) for 20 min at RT. Afterwards, glass slides were incubated with $50 \mu \mathrm{l}$ of a 1:50 diluted rabbit polyclonal EndoG antibody (Abcam, Cambridge, US) in blocking buffer. After 45 min of incubation time, slides were washed three times with PBS and blocked for further $5 \mathrm{~min}$ in the blocking solution. Anti-rabbit antibody conjugated with FITC was applied in the same manner for $30 \mathrm{~min}$. At last, 7-AAD $(1 \mu \mathrm{g} / \mathrm{ml})$ was added to blocking buffer for $30 \mathrm{~min}$. Glass slides were washed with PBS twice and embedded in $7 \mu \mathrm{DABCO}$. Analysis followed in a confocal microscope (Zeiss Axiophot).

\subsection{Western Blot}

Cells were harvested and lysed for $30 \mathrm{~min}$ on ice in a lysis buffer containing $50 \mathrm{mM}$ Tris- $\mathrm{HCl}, \mathrm{pH} 7.5,150 \mathrm{mM} \mathrm{NaCl}, 1 \%$ NP-40, 0.1\% SDS, 0.5\% Na-deoxycholate, $0.2 \mathrm{mM}$ phenylmethylsulfonyl-fluoride, $1 \mathrm{mM} \mathrm{NaF}, 10 \mu \mathrm{g} / \mathrm{ml}$ aprotinin, $10 \mu \mathrm{g} / \mathrm{ml}$ leupeptin. The lysates were centrifuged at $20000 \mathrm{~g}$ for $10 \mathrm{~min}$ at $4{ }^{\circ} \mathrm{C} .30 \mu \mathrm{g}$ of protein for each sample was separated on a $12.5 \%$ SDS-polyacrylamide gel. After 
electrophoresis, the proteins were transferred to PVDF membranes by wet electroblotting in a buffer containing $25 \mathrm{mM}$ Tris- $\mathrm{HCl}, 190 \mathrm{mM}$ glycine, 0.5\% SDS, $10 \%$ methanol. Transfer was controlled by staining the membrane with Ponceau S. Membrane was blocked in 5\% non-fat dried milk in TBS-T [20 mM Tris- $\mathrm{HCl} \mathrm{pH} 7.6$, $137 \mathrm{mM} \mathrm{NaCl}, 0.1 \%$ Tween 20] for $1 \mathrm{~h}$ at RT. Incubation with the anti-EndoG antibody (Abcam, Cambridge, US) was performed for $1 \mathrm{~h}$ at RT; the membrane was washed twice with TBS-T and incubated with an anti-rabbit antibody from Dako (Glastrup, Denmark) conjugated with horseradish peroxidase (HRP) for $30 \mathrm{~min}$. Immunoreactive proteins were detected using an enhanced chemiluminescence system (Amersham Life Science, Braunschweig, Germany).

\subsection{Caspase activity assay}

The Apo-ONE Homogeneous Caspase-3/7 Assay Kit obtained from Promega was used according to the protocol. Briefly, 70000 cells per 96 -well were used in $70 \mu \mathrm{l}$ volume; $100 \times$ substrate and buffer were mixed and $70 \mu$ of the mixture was added to the cells. Background measurement was carried out with empty medium without cells; normal measurement was performed in duplicates measured at different time points with multiple reads per well using a TECAN® fluorimeter. Standard deviation was calculated from different reads of two wells. Fluorescence was measured using $485 \mathrm{~nm}$ excitation and $530 \mathrm{~nm}$ emission wavelength.

\subsection{Subcellular fractionation using Qiagen Qproteome® Cell compartment Kit}

$5 \times 10^{6}$ of early passage and $3 \times 10^{6}$ of late passage HUVEC NS5 were used. Cells were detached and washed with ice-cold PBS and centrifuged at $500 \times \mathrm{g}$ for $10 \mathrm{~min}$ at $4^{\circ} \mathrm{C}$. The cell pellets were resuspended in $2 \mathrm{ml}$ ice-cold PBS, transferred into microcentrifuge tubes and centrifuged again at $500 \times \mathrm{g}$ for $10 \mathrm{~min}$ at $4^{\circ} \mathrm{C}$. The cell 
pellets were resuspended in $1 \mathrm{ml}$ ice-cold Extraction buffer CE1 by pipetting up and down. Solutions was incubated for $10 \mathrm{~min}$ in an end-over-end shaker at $4^{\circ} \mathrm{C}$. The lysates were centrifuged at $1000 \times \mathrm{g}$ for $10 \mathrm{~min}$ at $4^{\circ} \mathrm{C}$. The supernatants (fraction $1 /$ cytosolic proteins) were transferred into fresh microcentrifugation tubes. The pellets were resuspended with $1 \mathrm{ml} \mathrm{CE} 2$ buffer and incubated for $30 \mathrm{~min}$ in an end-over-end shaker. Suspension were centrifuged at $6000 \mathrm{xg}$ for $10 \mathrm{~min}$ at $4^{\circ} \mathrm{C}$. Supernatants (fraction 2 / membrane proteins) were transferred into fresh microcentrifugation tubes. $7 \mu$ l Benzoate was mixed with $13 \mu \mathrm{l}$ distilled $\mathrm{H}_{2} \mathrm{O}$, added to each pellet and incubated for $15 \mathrm{~min}$ at room temperature. After incubation time $500 \mu \mathrm{l}$ ice-cold Extraction buffer CE3 was added to the solutions, incubated for 10 min at $4^{\circ} \mathrm{C}$ on an end-over-end shaker. The mixtures were centrifuged at $6800 \times \mathrm{g}$ for $10 \mathrm{~min}$ at $4^{\circ} \mathrm{C}$. Supernatant (fraction 3 / nuclear proteins) were transferred to fresh tubes and stored on ice.

Different fractions were applied on a 10\% SDS-polyacrylamide gel loading $15 \mu \mathrm{l}$ of fraction $1,25 \mu \mathrm{l}$ of fraction 2 and $35 \mu \mathrm{l}$ of fraction 3 to load equal protein contents. To qualify the fractionation process, immunodetection was carried out in the same way as described in 2.6. using a corresponding antibody per fraction For cytosolic proteins M2PK (ScheBo, Germany), for membrane proteins anti-OxPhos Complex V subunit (Invitrogen, Austria) and for nuclear proteins p84 (Abcam, Cambridge, US) antibodies were used. 


\section{Results}

\subsection{Senescence-associated relocalization of EndoG}

To address a potential role of EndoG and its subcellular relocalization in senescenceassociated cell death of HUVEC, young and senescent cells were stained with antibodies to EndoG. To reveal a potential nuclear localization of EndoG, cells were counterstained with the DNA-specific nuclear dye 7-AAD. In young HUVEC, cytosolic localization of EndoG was observed, consistent with its known localization in mitochondria in healthy unstressed cells (Fig.1, upper panel). When EndoG was stained in senescent cultures, about $20-30 \%$ of the cells displayed nuclear localization of EndoG. This was particularly evident in cells with an irregular nuclear shape, indicative of cells undergoing apoptosis (Fig.1, lower panel). To corroborate these findings, early and late passage HUVEC were fractionated in a cytosolic, membrane and nuclear part where in both membrane and nuclear fractions, the EndoG signal was visible. The fractions were also probed with antibodies staining marker proteins known to be in the cytosolic, membrane and nuclear fraction. When comparing the amount of EndoG in the membrane fraction, early and late passages look the same but when comparing the nuclear fraction, the signal was stronger in late passage HUVEC. These results suggest that mitochondrial EndoG translocates to the nucleus in senescence-associated endothelial cell apoptosis.

\subsection{Functional consequences of EndoG inactivation}

To further address the role of EndoG in senescence-associated cell death, lentiviral vectors were constructed, which are suitable to knock down EndoG which is expressed in both young and, to a lesser extent, in senescent HUVEC (Fig.2A). Starting with five different knock down constructs, transfected in U2OS and analysed 
by Western blot and immunofluorescence (data not shown), the two most promising ones (sh32 and sh35) were used in this study. Early passage and late passage HUVEC of two different donors were infected with lentiviral vectors carrying two different EndoG specific shRNA sequences, for control, a scrambled virus carrying a nonspecific (scrambled) shRNA was used. The knockdown was followed by Western blot (Fig.2 B) suggesting that significant reduction of EndoG protein levels could be obtained. Functional consequences of EndoG knock down were subsequently monitored. We found that knocking down EndoG in both early passage and late passage cells led to a significant delay in cell proliferation (Fig.2). This was accompanied by an increase in the percentage of cells staining positive for senescence-associated B-galactosidase (Fig.2), suggesting that depletion of EndoG from human endothelial cells induces premature senescence. In yeast, EndoG was shown to be essential for mitochondrial function (Buttner et al., 2007a). To address, whether EndoG affects mitochondrial function in human endothelial cells, mitochondrial membrane potential was determined by staining with JC-1, a dye, which is sensitive to changes in mitochondrial membrane potential (Fig.3A). To control the experiment, mitochondrial membrane potential in young HUVEC was also measured with and without addition of the uncoupling agent FCCP. As expected, mitochondrial membrane potential was reduced to background levels by FCCP treatment. Under the same conditions, we found that knocking down EndoG in two different HUVEC strains by two different shRNA vectors had no significant effect on mitochondrial membrane potential (data not shown).

\subsection{EndoG and endothelial cell death}

Since cellular senescence of human endothelial cells is associated with an increased rate of spontaneous apoptosis, the effect of EndoG depletion on the rate of apoptosis 
was monitored. To quantitate the rate of apoptosis, cells were permeabilized and DNA stained with propidium iodide; the percentage of subG1 fragments was determined by flow cytometry, increased from $16 \pm 3 \%$ in control cells to $36 \pm 4 \%$ in EndoG-depleted cells (Fig.3B, and data not shown). This experiment revealed a significant increase in apoptotic cell death as a result of EndoG knockdown, suggesting that EndoG is required for optimal survival of human endothelial cells. Increased apoptotic cell death was also confirmed by a Caspase-3/7 activity assay (data not shown), Interestingly, the group of cells with 4N DNA content, which contains tetraploid cells in G1 phase (Wagner et al., 2001) was significantly reduced upon depletion of EndoG (Fig.3 B). This could reflect the general anti-proliferative effect of EndoG knockdown; alternatively, the absence of cells with a DNA content of $4 \mathrm{~N}$ may also reflect preferential killing of polyploid cells by EndoG knockdown, as described previously (Buttner et al. 2007b). More work will be required to address this point.

As it was reported that EndoG controls the balance between apoptosis and necrotic cell death in yeast cells (Buttner et al., 2007a), we also addressed the question, whether necrotic cell death may be modulated by EndoG knockdown. To monitor EndoG-dependent effects on necrosis, living cells were stained with propidium iodide, the uptake of which is characteristic of necrotic, but not apoptotic cell death (Fig.3C). Senescent HUVEC contained about $2.5 \%$ of necrotic cells, and this amount was slightly reduced by depletion of EndoG. Together these results suggest that EndoG protects human endothelial cells from apoptosis and at the same time increases the amount of necrotic cell death. 


\section{Discussion}

We show here that Endonuclease $G$ is localized in the mitochondria in young human endothelial cells and appears in the nucleus in senescent HUVEC cultures, suggesting that senescence-associated cell death in human cells involves EndoG. This is further supported by our observation that knocking down EndoG in human endothelial cells leads to premature senescence, irrespective of the passage number at infection. Surprisingly, EndoG knockdown had no significant effect on mitochondrial membrane potential, but led to a significant increase in apoptotic cell death. Finally, we observed a trend for a decrease in necrosis in cells depleted of EndoG.

\subsection{Role of endonuclease $G$ in cell death and disease}

Although well described as a potent inducer of caspase-independent cell death in response to stress, the physiological role of endonuclease $G$ in mammalian cells has not been fully established. A former study showing the necessity of EndoG in embryogenesis (Zhang et al., 2003) couldn't be verified by later studies, where EndoG knockout mice showed no deficiency in apoptosis or had any other phenotype (David et al., 2006; Irvine et al., 2005). Recent data from yeast established a mode of action for the yeast homolog of EndoG, and suggested that EndoG can have both vital and lethal activity, depending on the functional status of the mitochondria. Moreover the available data in yeast suggest a shift from age-associated apoptosis to necrosis upon depletion of EndoG (Buttner et al., 2007a). Recently, an inhibitor of EndoG (EndoGl) was found in the D. melanogaster gene cg4930 which consists of 2 homologous domains, each of them able to bind one EndoG nuclease (Temme et al., 2009). The crystal structure of the complex was resolved which supported the 2:1 stoichiometry (Loll et al., 2009). The group proposed a life insurance function for 
EndoGl for leakage of mitochondria by release of EndoGl from the nucleus and binding EndoG in the cytosol. No human homolog was found yet. Nuclear localization of EndoG has also been observed in a variety of age-associated pathologies. Thus, cerebral ischemia (Lee et al., 2005; Nielsen et al., 2009) and muscle atrophy (Leeuwenburgh et al., 2005; Marzetti et al., 2008) have been connected to a nuclear translocation of EndoG, resulting in apoptosis and degeneration.

\subsection{Endothelial cell senescence and cell death in vascular pathology}

For ageing of the vascular system, a tissue-damaging role of apoptosis is well established (Heinrich and Holz, 1998). Arteriosclerosis, a major age-related disease of humans, is accompanied by a degeneration of vascular endothelial cells and vascular smooth muscle cells due to programmed cell death. In this context, the activation of the cellular suicide pathway leading to apoptosis of the endothelial cells represents an initial step in the development of arteriosclerotic lesions (Bennett, 1999). Increased incidence of apoptosis in vitro was also observed when vascular smooth muscle cells from human atherosclerotic plaques were grown in vitro and compared to control cells (Bennett et al., 1998). Whereas there is compelling evidence that cell death by apoptosis contributes to vascular damage under pathological conditions (e.g., arteriosclerosis), the role of apoptosis during normal vascular ageing remains to be established. Our finding that endothelial cells undergo ageassociated apoptosis during in vitro ageing (Wagner et al., 2001) may provide a good model system for further studies. Age-related apoptosis is believed to play an important role during tissue ageing (Adams et al., 1996; Nicosia et al., 1995; Usami et al., 1997), and in vitro senescence of HUVEC may provide a new model for agerelated apoptosis that could be useful for studying the role of intrinsic and extrinsic ageing in certain vascular pathologies, e.g., arteriosclerosis (Bennett, 1999). 
Whereas the role of cellular senescence in normal ageing is still controversial, cellular senescence has been widely used as a model system to study ageing of various human tissues. Experimental evidence suggests that the occurrence of cells with a senescence-like phenotype is not restricted to tissue culture experiments. Senescent cells have been described in mitotic tissue of ageing rodents (Krishnamurthy et al., 2004), non-human primates (Jeyapalan et al., 2007), as well as in human aged tissues, such as the skin (Dimri et al., 1995; Ressler et al., 2006), the vascular system (Vasile et al., 2001) and the kidney (Melk et al., 2004). The premature appearance of senescent cells in the vascular endothelium has been associated with the onset of age-associated cardiovascular diseases, such as arteriosclerosis (Minamino et al., 2002). In light of these findings, our current observation, by both immunofluorescence and biochemical fractionation studies, that EndoG localizes to the nucleus in senescent endothelial cells and its role in modulating cell death may be of relevance for vascular diseases; however, more work will be required to elucidate the precise role of EndoG in age-associated vascular pathology. 


\section{Acknowledgements}

We thank Brigitte Jenewein for excellent technical assistance. This work was supported by an FP6 grant (MiMage) from the EU and by the Austrian Science Funds (FWF; NFNS93). 


\section{Legends to Figures}

Fig.1: Immunodetection of endogenous EndoG in human umbilical vein endothelial cells (HUVEC)

A. The upper row shows young cells at passage 7 , the lower row senescent cells at passage 20. Anti-EndoG antibody was stained in green, nucleus was stained with 7AAD (red). Images were taken in the same microscope with identical settings.

B. Fractionation analysis of early and late passage HUVEC, showing cytosolic (1), membrane (2) and nuclear fraction (3). For each fraction a marker protein antibody was probed. EndoG is visible in the membrane fraction together with the mitochondrial marker OxPhos Complex $\mathrm{V}$ subunit, as well as in the nuclear fraction colocalizing with p84. No EndoG was found in the cytosol colocalizing with M2-PK.

Fig.2: Effects of EndoG knockdown on cell proliferation and senescence.

Experiments were done with two different donors (HUVEC \#1 in B, HUVEC \#5 in C) at early (ep) and late (lp) passages.

A. Extracts were prepared of HUVEC in early and late passage as indicated and probed for EndoG by Western blot.

B. Western blot probed with anti-EndoG shows reduced levels in knockdown samples (sh32, sh35) for early passage HUVEC two weeks post infection compared to control (upper left). The percentage of cells staining positive for senescence-associated $\beta$ Galactosidase (SA- $\beta$-Gal) and the effects of knockdown are shown (upper right). Population doublings (PDL) are indicated in HUVEC infected with scrambled RNA and with EndoG shRNA (lower panel). 
C. Western blot probed with anti-EndoG shows reduced levels in knockdown samples (sh32, sh35) for late passage HUVEC two weeks post infection compared to control (upper left). The percentage of cells staining positive for senescenceassociated $\beta$-Galactosidase (SA- $\beta$-Gal) and the effects of knockdown are shown (upper right). Population doublings (PDL) are indicated in HUVEC infected with scrambled RNA and with EndoG shRNA (lower panel).

Fig.3: Effects of EndoG knockdown on cell death

A. The ratio between a number of cells with high mitochondrial membrane potential $(\Delta \Psi)$ and the uncoupled state is shown. $\Delta \Psi$ has been determined in JC-1 stained cells using FACS. As a positive control serve early passage (ep) cells, as a negative control the cells pre-treated with FCCP. Two different donors (HUVEC \#1 and \#5) were analysed in late passage (Ip).

B. HUVEC in late passage were permeabilized and stained with propidium iodide. Flow cytometry was performed and the percentage of subG1 DNA fragments was determined, as a measure for apoptotic cell death.

C. HUVEC in late passage, as indicated, were directly stained with propidium iodide. Flow cytometry was performed and the percentage of PI positive cells was determined, as a measure for necrotic cell death. 


\section{References}

Adams, J.D., Mukherjee, S.K., Klaidman, L.K., Chang, M.L., Yasharel, R., 1996. Apoptosis and oxidative stress in the aging brain. Ann N Y Acad Sci 786, 135-51.

Bennett, M.R., Macdonald, K., Chan, S.W., Boyle, J.J., Weissberg, P.L., 1998. Cooperative interactions between RB and p53 regulate cell proliferation, cell senescence, and apoptosis in human vascular smooth muscle cells from atherosclerotic plaques. Circ Res 82, 704-12.

Bennett, M.R., 1999. Apoptosis of vascular smooth muscle cells in vascular remodelling and atherosclerotic plaque rupture. Cardiovasc Res 41, 361-8.

Bernardi, P., Petronilli, V., Di Lisa, F., Forte, M., 2001. A mitochondrial perspective on cell death. Trends Biochem Sci 26, 112-7.

Bratton, S.B., Walker, G., Srinivasula, S.M., Sun, X.M., Butterworth, M., Alnemri, E.S., Cohen, G.M., 2001. Recruitment, activation and retention of caspases- 9 and -3 by Apaf- 1 apoptosome and associated XIAP complexes. Embo J 20, 998-1009.

Buttner, S., Eisenberg, T., Carmona-Gutierrez, D., Ruli, D., Knauer, H., Ruckenstuhl, C., Sigrist, C., Wissing, S., Kollroser, M., Frohlich, K.U., Sigrist, S., Madeo, F., 2007a. Endonuclease G regulates budding yeast life and death. Mol Cell 25, 233-46.

Buttner, S., Carmona-Gutierrez, D., Vitale, I., Castedo, M., Ruli, D., Eisenberg, T., Kroemer, G., Madeo, F., 2007b. Depletion of endonuclease G selectively kills polyploid cells. Cell Cycle 6, 1072-6.

Campisi, J., 1998. The role of cellular senescence in skin aging. J Investig Dermatol Symp Proc 3, 1-5.

Chen, Q., Ames, B.N., 1994. Senescence-like growth arrest induced by hydrogen peroxide in human diploid fibroblast F65 cells. Proc Natl Acad Sci U S A 91, 4130-4.

Colavitti, R., Finkel, T., 2005. Reactive oxygen species as mediators of cellular senescence. IUBMB Life 57, 277-81.

Cote, J., Renaud, J., Ruiz-Carrillo, A., 1989. Recognition of (dG)n.(dC)n sequences by endonuclease G. Characterization of the calf thymus nuclease. J Biol Chem 264, 3301-10.

Cote, J., Ruiz-Carrillo, A., 1993. Primers for mitochondrial DNA replication generated by endonuclease G. Science 261, 765-9.

David, K.K., Sasaki, M., Yu, S.W., Dawson, T.M., Dawson, V.L., 2006. EndoG is dispensable in embryogenesis and apoptosis. Cell Death Differ 13, 1147-55.

Dimri, G.P., Lee, X., Basile, G., Acosta, M., Scott, G., Roskelley, C., Medrano, E.E., Linskens, M., Rubelj, I., Pereira-Smith, O., Smith, J., 1995. A biomarker that identifies senescent human cells in culture and in aging skin in vivo. Proc Natl Acad Sci U S A 92, 9363-7.

Effros, R.B., 1996. Insights on immunological aging derived from the T lymphocyte cellular senescence model. Exp Gerontol 31, 21-7.

Haake, A.R., Roublevskaia, I., Cooklis, M., 1998. Apoptosis: a role in skin aging? J Investig Dermatol Symp Proc 3, 28-35.

Hampel, B., Malisan, F., Niederegger, H., Testi, R., Jansen-Durr, P., 2004. Differential regulation of apoptotic cell death in senescent human cells. Exp Gerontol 39, 1713-21.

Heinrich, H., Holz, J., 1998. Myocardial apoptosis in the overloaded and the aging heart: a critical role of mitochondria? Eur Cytokine Netw 9, 693-5.

Irvine, R.A., Adachi, N., Shibata, D.K., Cassell, G.D., Yu, K., Karanjawala, Z.E., Hsieh, C.L., Lieber, M.R., 2005. Generation and characterization of endonuclease G null mice. Mol Cell Biol 25, 294-302.

Jeyapalan, J.C., Ferreira, M., Sedivy, J.M., Herbig, U., 2007. Accumulation of senescent cells in mitotic tissue of aging primates. Mech Ageing Dev 128, 36-44.

Krishnamurthy, J., Torrice, C., Ramsey, M.R., Kovalev, G.I., Al-Regaiey, K., Su, L., Sharpless, N.E., 2004. Ink4a/Arf expression is a biomarker of aging. J Clin Invest 114, 1299-307.

Kurz, D.J., Decary, S., Hong, Y., Trivier, E., Akhmedov, A., Erusalimsky, J.D., 2004. Chronic oxidative stress compromises telomere integrity and accelerates the onset of senescence in human endothelial cells. J Cell Sci 117, 2417-26. 
Lee, B.I., Lee, D.J., Cho, K.J., Kim, G.W., 2005. Early nuclear translocation of endonuclease G and subsequent DNA fragmentation after transient focal cerebral ischemia in mice. Neurosci Lett 386, 237.

Leeuwenburgh, C., Gurley, C.M., Strotman, B.A., Dupont-Versteegden, E.E., 2005. Age-related differences in apoptosis with disuse atrophy in soleus muscle. Am J Physiol Regul Integr Comp Physiol 288, R1288-96.

Li, L.Y., Luo, X., Wang, X., 2001. Endonuclease $G$ is an apoptotic DNase when released from mitochondria. Nature 412, 95-9.

Loll, B., Gebhardt, M., Wahle, E., Meinhart, A., 2009. Crystal structure of the EndoG/EndoGI complex: mechanism of EndoG inhibition. Nucleic Acids Res.

Marzetti, E., Wohlgemuth, S.E., Lees, H.A., Chung, H.Y., Giovannini, S., Leeuwenburgh, C., 2008. Agerelated activation of mitochondrial caspase-independent apoptotic signaling in rat gastrocnemius muscle. Mech Ageing Dev 129, 542-9.

Melk, A., Schmidt, B.M., Takeuchi, O., Sawitzki, B., Rayner, D.C., Halloran, P.F., 2004. Expression of p16INK4a and other cell cycle regulator and senescence associated genes in aging human kidney. Kidney Int 65, 510-20.

Migliaccio, E., Giorgio, M., Mele, S., Pelicci, G., Reboldi, P., Pandolfi, P.P., Lanfrancone, L., Pelicci, P.G., 1999. The p66shc adaptor protein controls oxidative stress response and life span in mammals. Nature 402, 309-13.

Minamino, T., Miyauchi, H., Yoshida, T., Ishida, Y., Yoshida, H., Komuro, I., 2002. Endothelial cell senescence in human atherosclerosis: role of telomere in endothelial dysfunction. Circulation 105, 1541-4.

Nicholson, D.W., 1999. Caspase structure, proteolytic substrates, and function during apoptotic cell death. Cell Death Differ 6, 1028-42.

Nicoletti, I., Migliorati, G., Pagliacci, M.C., Grignani, F., Riccardi, C., 1991. A rapid and simple method for measuring thymocyte apoptosis by propidium iodide staining and flow cytometry. J Immunol Methods 139, 271-9.

Nicosia, S.V., Diaz, J., Nicosia, R.F., Saunders, B.O., Muro-Cacho, C., 1995. Cell proliferation and apoptosis during development and aging of the rabbit corpus luteum. Ann Clin Lab Sci 25, 143-57.

Nielsen, M., Lambertsen, K.L., Clausen, B.H., Meldgaard, M., Diemer, N.H., Zimmer, J., Finsen, B., 2009. Nuclear translocation of endonuclease $G$ in degenerating neurons after permanent middle cerebral artery occlusion in mice. Exp Brain Res 194, 17-27.

Parrish, J., Li, L., Klotz, K., Ledwich, D., Wang, X., Xue, D., 2001. Mitochondrial endonuclease G is important for apoptosis in C. elegans. Nature 412, 90-4.

Ressler, S., Bartkova, J., Niederegger, H., Bartek, J., Scharffetter-Kochanek, K., Jansen-Durr, P., Wlaschek, M., 2006. p16INK4A is a robust in vivo biomarker of cellular aging in human skin. Aging Cell 5, 379-89.

Schafer, P., Scholz, S.R., Gimadutdinow, O., Cymerman, I.A., Bujnicki, J.M., Ruiz-Carrillo, A., Pingoud, A., Meiss, G., 2004. Structural and functional characterization of mitochondrial EndoG, a sugar nonspecific nuclease which plays an important role during apoptosis. J Mol Biol 338, 217-28.

Seluanov, A., Gorbunova, V., Falcovitz, A., Sigal, A., Milyavsky, M., Zurer, I., Shohat, G., Goldfinger, N., Rotter, V., 2001. Change of the death pathway in senescent human fibroblasts in response to DNA damage is caused by an inability to stabilize p53. Mol Cell Biol 21, 1552-64.

Shawi, M., Autexier, C., 2008. Telomerase, senescence and ageing. Mech Ageing Dev 129, 3-10.

Temme, C., Weissbach, R., Lilie, H., Wilson, C., Meinhart, A., Meyer, S., Golbik, R., Schierhorn, A., Wahle, E., 2009. The Drosophila melanogaster Gene cg4930 Encodes a High Affinity Inhibitor for Endonuclease G. J Biol Chem 284, 8337-48.

Unterluggauer, H., Hampel, B., Zwerschke, W., Jansen-Durr, P., 2003. Senescence-associated cell death of human endothelial cells: the role of oxidative stress. Exp Gerontol 38, 1149-60.

Usami, S., Takumi, Y., Fujita, S., Shinkawa, H., Hosokawa, M., 1997. Cell death in the inner ear associated with aging is apoptosis? Brain Res 747, 147-50. 
Varecha, M., Amrichova, J., Zimmermann, M., Ulman, V., Lukasova, E., Kozubek, M., 2007. Bioinformatic and image analyses of the cellular localization of the apoptotic proteins endonuclease G, AIF, and AMID during apoptosis in human cells. Apoptosis 12, 1155-71.

Vasile, E., Tomita, Y., Brown, L.F., Kocher, O., Dvorak, H.F., 2001. Differential expression of thymosin beta- 10 by early passage and senescent vascular endothelium is modulated by VPF/VEGF: evidence for senescent endothelial cells in vivo at sites of atherosclerosis. Faseb J 15, 458-66.

von Zglinicki, T., Saretzki, G., Docke, W., Lotze, C., 1995. Mild hyperoxia shortens telomeres and inhibits proliferation of fibroblasts: a model for senescence? Exp Cell Res 220, 186-93.

Wagner, M., Hampel, B., Bernhard, D., Hala, M., Zwerschke, W., Jansen-Durr, P., 2001. Replicative senescence of human endothelial cells in vitro involves $G 1$ arrest, polyploidization and senescenceassociated apoptosis. Exp Gerontol 36, 1327-47.

Wang, E., 1995. Senescent human fibroblasts resist programmed cell death, and failure to suppress bcl2 is involved. Cancer Res 55, 2284-92.

Warner, H.R., Hodes, R.J., Pocinki, K., 1997. What does cell death have to do with aging? J Am Geriatr Soc 45, 1140-6.

Zhang, J., Block, E.R., Patel, J.M., 2002. Down-regulation of mitochondrial cytochrome c oxidase in senescent porcine pulmonary artery endothelial cells. Mech Ageing Dev 123, 1363-74.

Zhang, J., Dong, M., Li, L., Fan, Y., Pathre, P., Dong, J., Lou, D., Wells, J.M., Olivares-Villagomez, D., Van Kaer, L., Wang, X., Xu, M., 2003. Endonuclease $G$ is required for early embryogenesis and normal apoptosis in mice. Proc Natl Acad Sci U S A 100, 15782-7.

Zou, H., Henzel, W.J., Liu, X., Lutschg, A., Wang, X., 1997. Apaf-1, a human protein homologous to C. elegans CED-4, participates in cytochrome c-dependent activation of caspase-3. Cell 90, 405-13. 
A
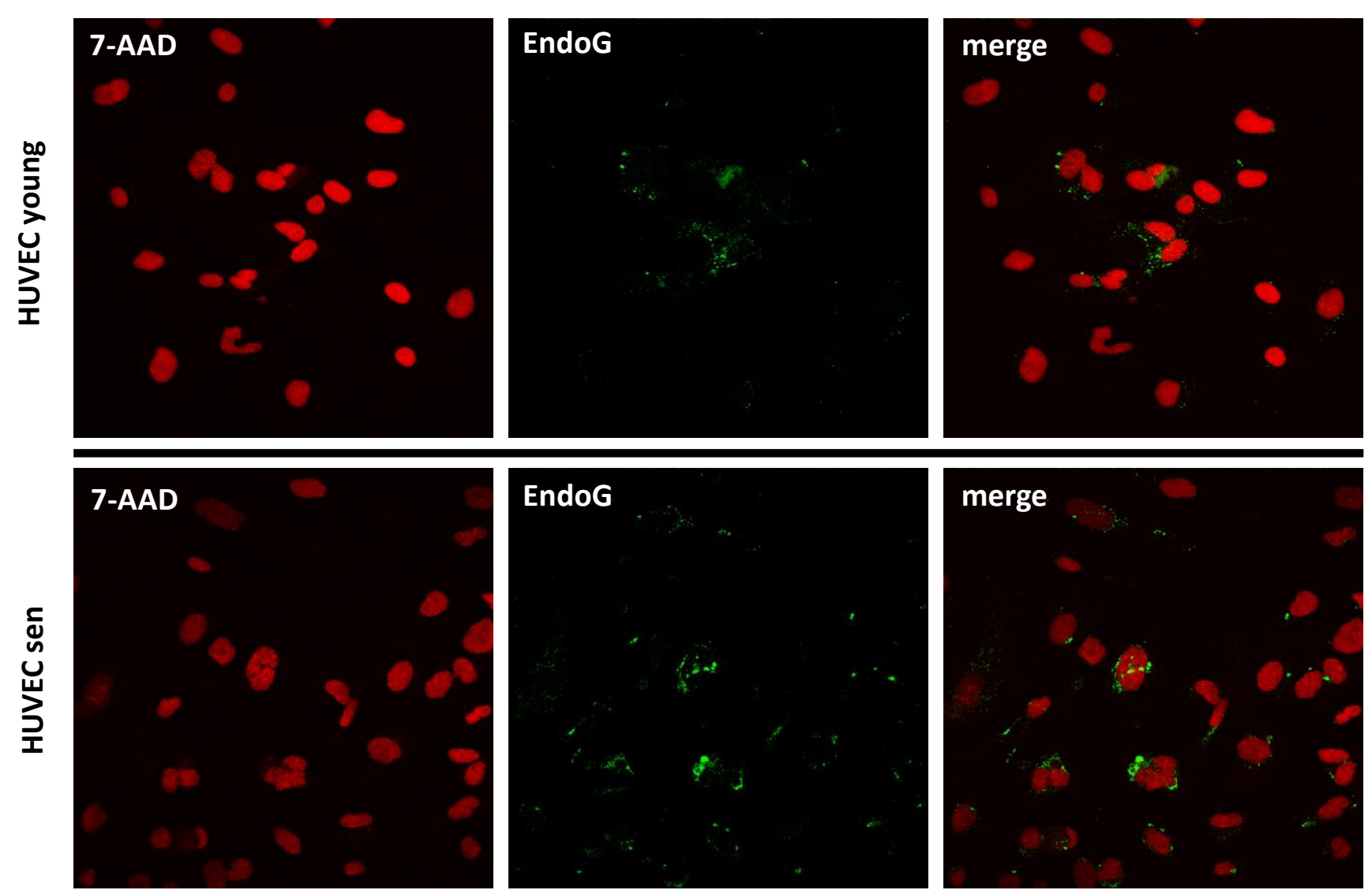

B

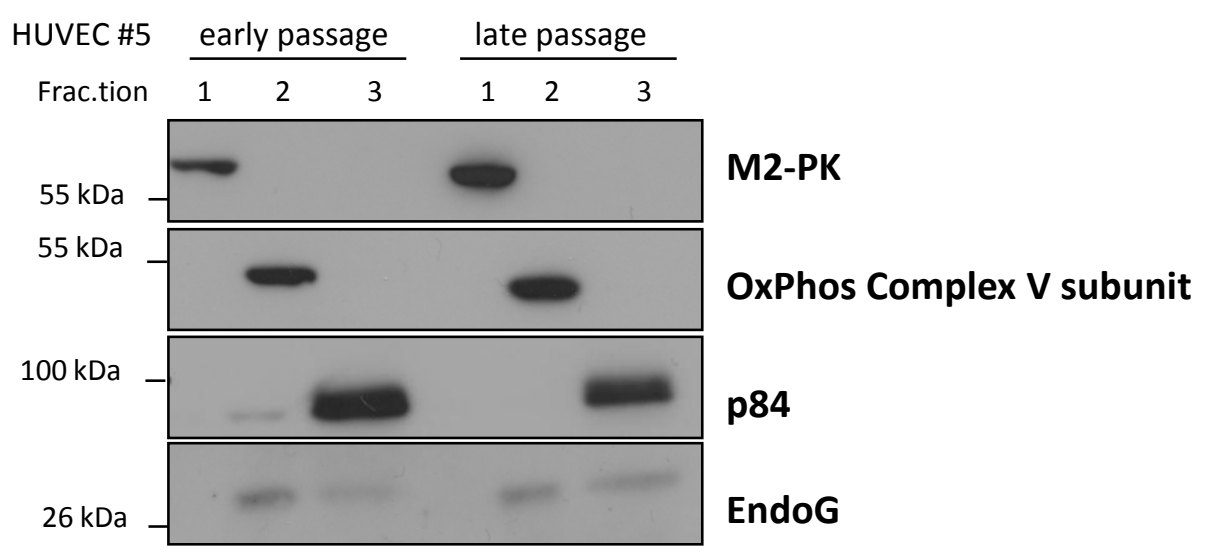

Fig. 1 


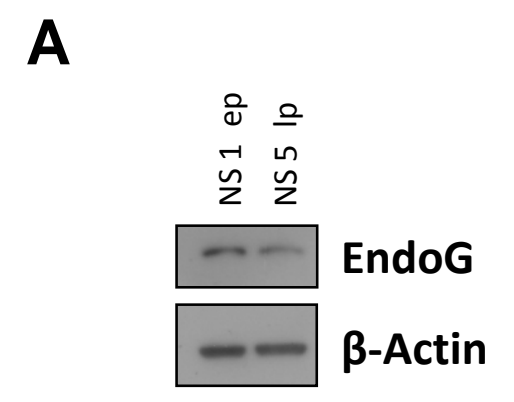

Fig. 2 
B
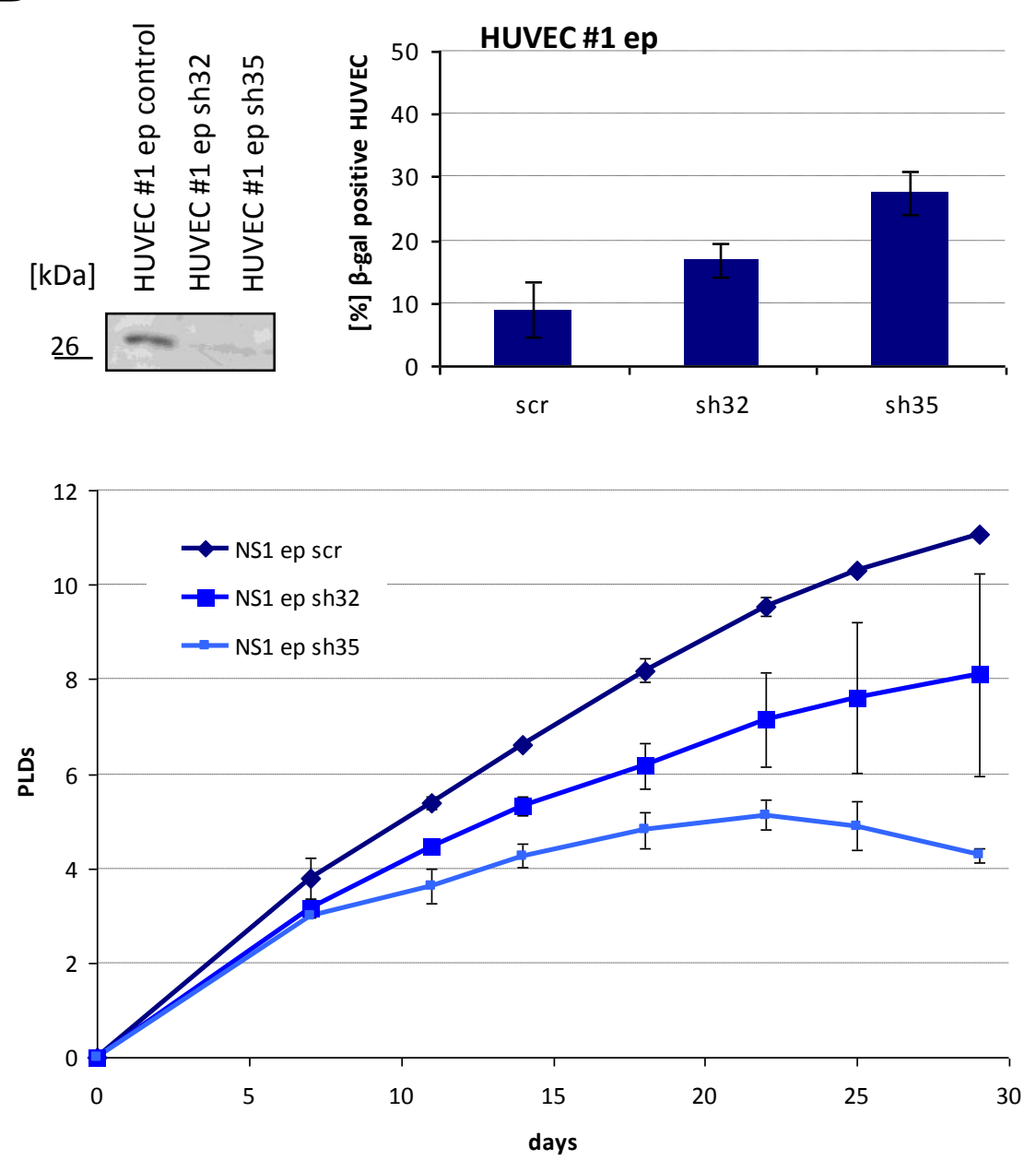

Fig. 2 
C
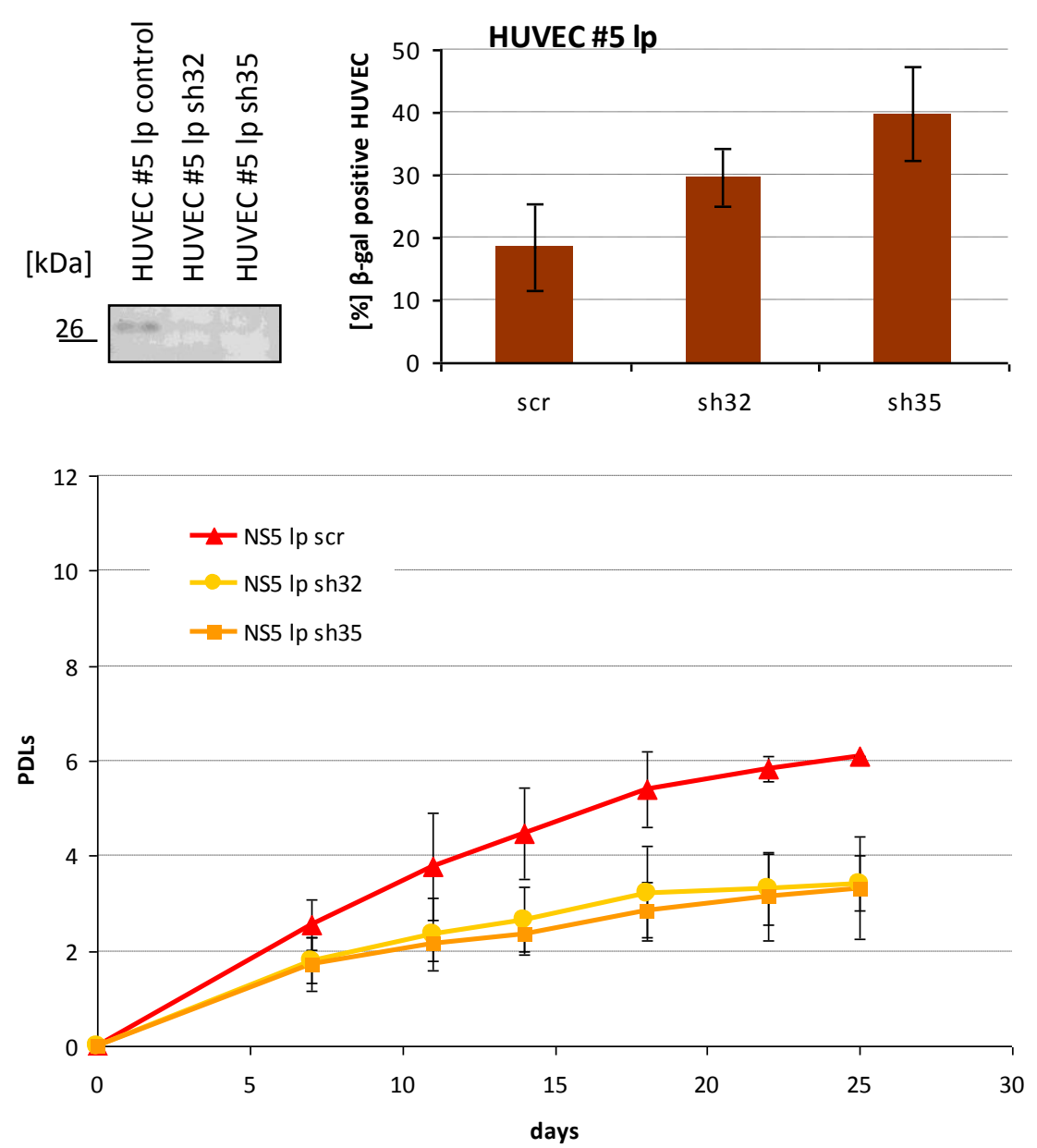

Fig. 2 
A

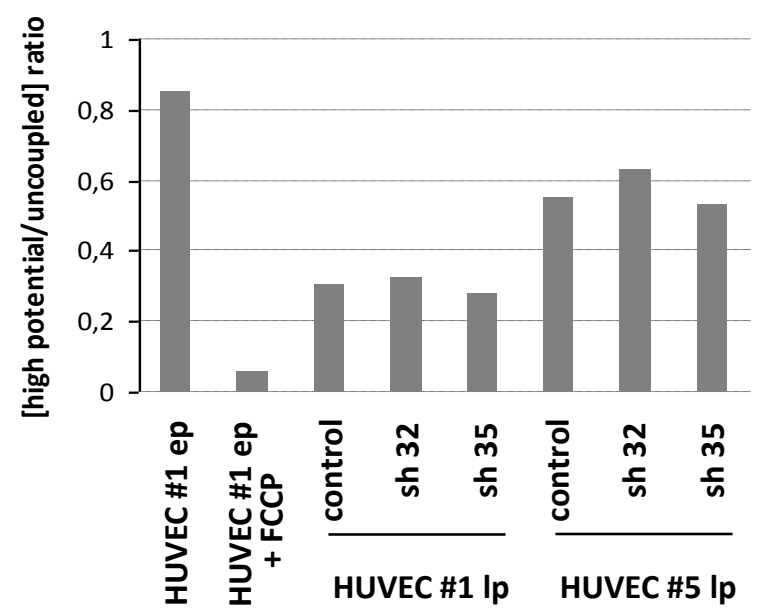

Fig. 3 


\section{B}
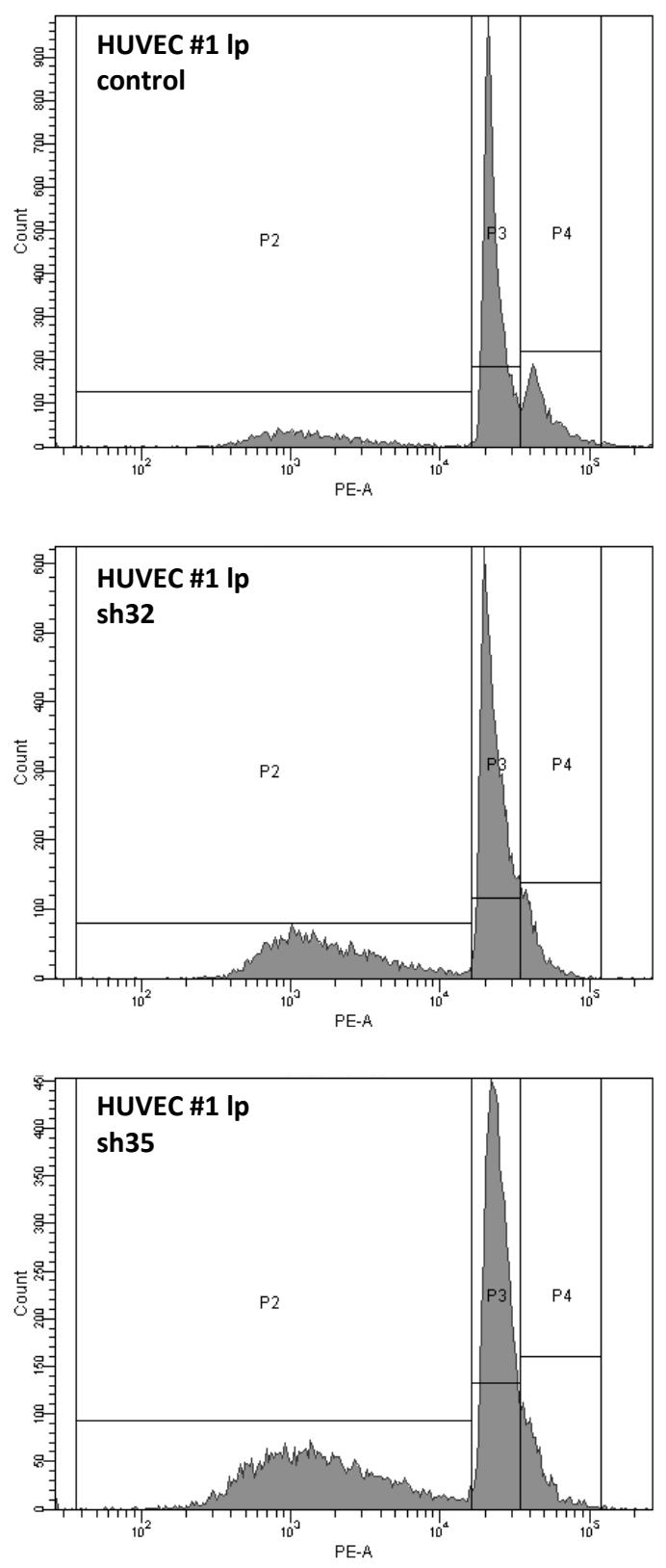

Fig. 3 


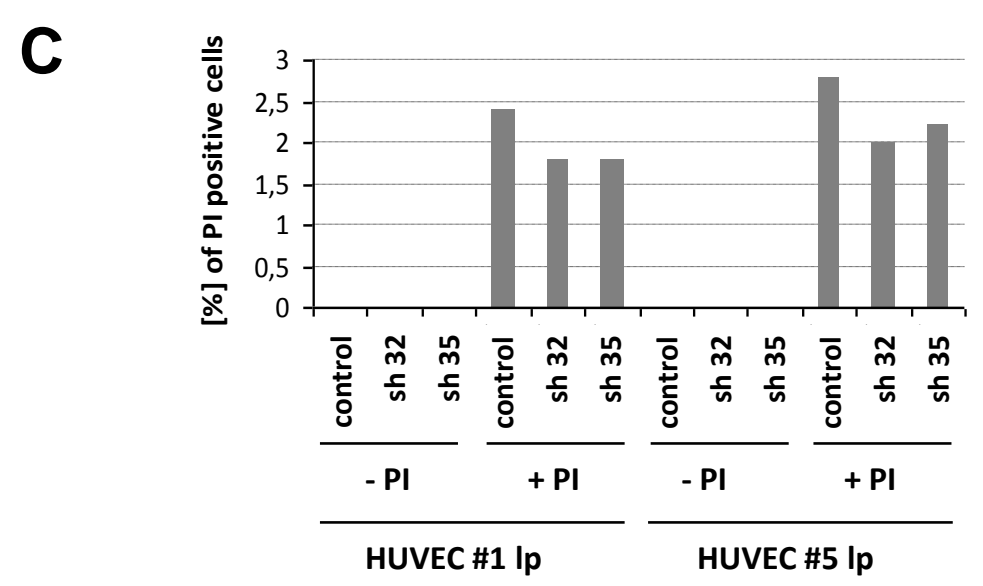

Fig. 3 